\title{
Association of apolipoprotein E polymorphisms and dietary factors in colorectal cancer
}

\author{
M Mrkonjic ${ }^{1,2,3}$, E Chappell 2,3, VV Pethe ${ }^{2,3}, M_{\text {Manno }}^{2,4}$, D Daftary ${ }^{5}$, CM Greenwood ${ }^{6}$, S Gallinger $^{2,7,8}$, \\ BW Zanke,9, JA Knight ${ }^{2,4,6}$ and B Bapat*,1,2,3
}

'Department of Laboratory Medicine and Pathobiology, University of Toronto, Toronto, ON, Canada M5G IL5; ${ }^{2}$ Samuel Lunenfeld Research Institute, Mount Sinai Hospital, Toronto, ON, Canada M5T 3L9; ' Department of Pathology and Laboratory Medicine, Mount Sinai Hospital, Toronto, ON, Canada M5G IX5; ${ }^{4}$ Prosserman Centre for Health Research, Mount Sinai Hospital, Toronto, ON, Canada M5T 3L9; ${ }^{5}$ Ontario Familial Colorectal Cancer Registry, Cancer Care Ontario, Toronto, ON, Canada M5G 3L7; ${ }^{6}$ Dalla Lana School of Public Health, University of Toronto, Toronto, ON, Canada M5T 3M7; 7 Department of Surgery, Mount Sinai Hospital, Toronto, ON, Canada M5G IX5; ${ }^{8}$ Department of Surgery, University of Toronto, Toronto, ON, Canada M5G IL5; ${ }^{9}$ Ottawa Health Research Institute, Ottawa, ON, Canada KIY 4E9

ApoE single nucleotide polymorphisms (SNPs) Cys II2Arg (Epsilon-4), and Arg158Cys (Epsilon-2) have been implicated in cardiovascular and Alzheimer's disease, but their role in colorectal cancer (CRC) has not been extensively studied. We investigated whether ApoE polymorphisms alone or in combination with dietary factors selectively contribute to mismatch-repair (MMR) proficient (microsatellite stable/low or MSS/L) vs deficient (microsatellite unstable or MSI-H) CRCs. We carried out a case-control study with $906 \mathrm{CRC}$ cases and 91I unaffected controls to examine the associations between ApoE polymorphisms and dietary factors and assessed their contribution to MSS/L and MSI-H CRCs. We used unconditional logistic regression to evaluate the associations between ApoE SNPs, tumour MSI status, and dietary factors after adjusting for age and sex. All statistical tests were twosided. No significant differences in ApoE genotype frequencies were observed between CRC cases and unaffected controls. We observed that increased dietary intake of total fat, saturated fat, cholesterol, and red meat was significantly associated with CRC Among non-ApoE4 carriers, $2-4$ and $>4$ red meat servings/week were associated with developing MSS/L CRC (OR $=1.51,95 \%$ CI I. I0-2.07 and $O R=1.80,95 \% \mathrm{Cl} \mid .30-2.48$, respectively), whereas among ApoE4 allele carriers, four or more red meat servings/ week were associated with MSI-H CRC $(\mathrm{OR}=4.62,95 \% \mathrm{Cl}$ I.20-17.77) when compared with the controls. ApoE isoforms modulate the risk of $\mathrm{MSI}-\mathrm{H}$ and MSS/L CRCs among high red meat consumers.

British Journal of Cancer (2009) I 00, 1966-1974. doi:I0.1038/sj.bjc.6605097 www.bjcancer.com

Published online 19 May 2009

(c) 2009 Cancer Research UK

Keywords: CRC: colorectal cancer; ApoE: apolipoprotein E; MMR: mismatch repair; MSI-H: high-frequency microsatellite instability; MSS/L: microsatellite stable/low-frequency microsatellite instability; SNP: single nucleotide polymorphism

Colorectal cancer (CRC) is a common malignancy and the second leading cause of cancer-related deaths in North America (Jemal et al, 2007). On the basis of mismatch-repair (MMR) functional status, CRCs can be subdivided into MMR-deficient, microsatellite unstable (MSI-H) and MMR-proficient, microsatellite stable (MSS) tumours. In addition to genetic alterations in tumour suppressor genes and oncogenes that are responsible for MSS tumours or defects in the DNA mismatch repair (Lynch and de la Chapelle, 2003), mutations and single nucleotide polymorphisms in genes involved in the metabolic pathways have also been implicated in CRC but to a lesser extent. Diets high in red and processed meat have been shown to increase risk of CRC, whereas diets rich in fruits, vegetables, and fibre lower CRC risk (Emmons et al, 2005; Ferrari et al, 2007). As dietary animal fat is a risk factor for CRC (Bautista et al, 1997; Slattery et al, 2000; Diergaarde et al, 2003; Wark et al, 2006), genetic alterations involved in the regulation of

*Correspondence: Dr B Bapat; E-mail: bapat@lunenfeld.ca Received 5 February 2009; revised 21 April 2009; accepted 24 April 2009; published online 19 May 2009 lipid transport and metabolism are potential susceptibility factors for colon cancer.

ApoE plays a multi-functional role in lipoprotein metabolism by acting as a high-affinity ligand for receptors of the LDL receptor family and serving as a cofactor in VLDL synthesis, as well as the hydrolysis of VLDL remnants in LDL production (Minihane et al, 2007). However, recent studies have identified ApoE functions other than lipid metabolism such as DNA synthesis, $\beta$-catenin localisation, cell proliferation, antioxidant abilities, angiogenesis, and metastasis that may play a role in CRC (Vogel et al, 1994; Grocott et al, 2001; Niemi et al, 2002; Cedazo-Minguez et al, 2003). The most widely studied polymorphisms in ApoE gene are Cys112Arg (rs429358) and Arg158Cys (rs7412), which create three distinct protein isoforms: ApoE2-epsilon2 (112Cys/158Cys), wild-type ApoE3-epsilon3 (112Cys/158Arg), and ApoE4-epsilon4 (112Arg/158Arg) (Weisgraber et al, 1981; Rall et al, 1982). ApoE4 is considered the high-risk isoform for chronic heart disease, Alzheimer's disease, and age-related cognitive decline (Corder et al, 1993; Wilson et al, 1996; Bretsky et al, 2003). However, the role of ApoE isoforms in CRC is not well established. All ApoE allelic variants are associated with distinct patterns of lipid 
transport and metabolism, and are shown to modulate enterohepatic metabolism of cholesterol and bile acids, which are implicated in promoting colorectal tumorigenesis (Debruyne et al, 2002; Minihane et al, 2007). Consequently, ApoE alleles are candidate risk factors for CRC. In a small study, ApoE4 was found to be protective from developing adenomas and carcinomas of the proximal colon (Kervinen et al, 1996), where the MSI-H subset of CRCs usually develop. A similar, but weak, inverse correlation of ApoE4 with proximal colonic location was reported among Australian CRC patients (Butler et al, 2001). MSI-H CRCs have distinct clinical and pathological manifestations from MSS CRCs such as: proximal colon location, mucinous histology, poor differentiation, Crohn-like reaction, tumour infiltrating lymphocytes (Alexander et al, 2001), and drug response (Elsaleh et al, 2001), and it is likely that distinct genetic and/or dietary risk factors contribute to these distinct CRC features. However, no study has evaluated the role of ApoE isoforms in CRC subtypes recognised by mismatch-repair deficient (MSI-H) and proficient (none or low microsatellite instability, MSS/L) profiles.

In this study, we investigated whether ApoE gene polymorphisms are associated with MSI-H and MSS/L CRC and whether they interact with dietary factors.

\section{MATERIALS AND METHODS}

\section{Study subjects}

The accrual of CRC patients and unaffected controls, the response rates, population characteristics, and ethnic backgrounds were described earlier (Mrkonjic et al, 2007; Raptis et al, 2007). Briefly, $\mathrm{CRC}$ cases and unaffected controls from the province of Ontario were obtained from the Ontario Familial Colorectal Cancer Registry (OFCCR). A total of 906 cases, aged 20-74 years, and diagnosed during the years 1997-2000, were identified for this study along with 911 unaffected controls. Ninety-five percent of participants in the OFCCR are of Caucasian ethnicity. Family history was collected by mailed questionnaires and was then used to construct pedigrees. Patients were classified by family risk. Further risk factor information was collected from two other mailed questionnaires and blood and tissue specimens were obtained. CRC patients were also stratified by family risk as described earlier by Cotterchio et al (2000). No apparent cases with familial adenomatous polyposis coli were included in the case series.

In addition to personal and family risk questionnaires, participants were also asked to complete a Food Frequency Questionnaire (FFQ). The FFQ was developed by the Epidemiology Program, Cancer Research Center of Hawaii and has been described earlier and validated (Cotterchio et al, 2008). Food frequency questionnaires were analysed using food composition databases that include values for macro- and micronutrients (Cotterchio et al, 2008). Data on saturated fat (grams), total fat (grams), and total cholesterol (milligrams), folacin (milligrams), and alcoholic beverages (per week) was obtained from the FFQ and was placed into quartiles. The frequency of red meat intake (servings per week) was obtained from a separate risk factor questionnaire and the values were also placed into quartiles. The research ethics boards of Mount Sinai Hospital and the University of Toronto approved all protocols.

\section{Molecular genetic analysis}

Single nucleotide polymorphism genotyping Genomic DNA was extracted from peripheral blood lymphocytes using phenolchloroform or the Qiagen DNA extraction kit (Qiagen Inc., Montgomery County, MD, USA) as reported earlier (Mrkonjic et al, 2007; Raptis et al, 2007). Restriction Fragment Length Polymorphism (RFLP) was used to initially genotype the ApoE polymorphisms in CRC cases as described earlier (Gioia et al, 1998). Briefly, the initial PCR yields an amplicon of $485 \mathrm{bp}$ of ApoE exon 4 containing both polymorphisms. The secondary, nested PCR yields a $300 \mathrm{bp}$ product. The conditions of both PCRs, primer sequences, and restriction digestion analysis have been described earlier (Gioia et al, 1998). HhaI digestion of the nested amplicon generated unique patterns of restriction fragments depending on the original genotype of the individual. ApoE2 and ApoE3 lack HhaI restriction site at codon 112 and ApoE2 lacks the HhaI restriction site at codon 158 . The restriction fragments were visualised through electrophoresis on a $4 \%$ agarose gel (Invitrogen, Burlington, Ontario, Canada).

With the availability of SNP genotyping arrays, we have genotyped CRC cases and unaffected controls for the ApoE4 SNP (rs429358) using the Illumina Golden Gate Assay (Illumina Inc., San Diego, CA, USA) as described earlier (Zanke et al, 2007). We used our previous RFLP genotyping of CRC cases for the rs429358 SNP to validate the genotyping calls. Because the ApoE2 SNP (rs7412) was not successfully genotyped using the Illumina Golden Gate Assay, we used TaqMan allelic discrimination assay to genotype the unaffected controls. The sequences of primers and probes are: forward primer CGCGATGCCGATGACCT, reverse primer GGCCCCGGCCTGGTAC, wild-type probe 6FAM-ACTGC CAGGCGCTTC-MGBNFQ, and variant probe VIC-ACTGCCAGG CACTTC-MGBNFQ. The conditions for the allelic discrimination reaction have been described earlier (Mrkonjic et al, 2007).

Additional independent validation for ApoE3/E4 was done on $55 \%$ of samples by TaqMan allelic discrimination assay as described earlier (MacLeod et al, 2001). The PCR conditions and primer/probe sequences have also been described earlier (MacLeod et al, 2001). All assays were run in 96-well polypropylene plates (Axygen Scientific, Union City, CA, USA) and the results were analysed using the Applied Biosystems 7900HT Sequence Detection system and accompanying software, SDS version 2.0 and/or 2.1 (Applied Biosystems, Foster City, CA, USA).

Tumour microsatellite instability (MSI) analysis MSI analysis was performed as described earlier (Raptis et al, 2007). Briefly, paraffinembedded colorectal tumour tissue of incident cases, and normal tissue from the same patient, were microdissected in areas with $>70 \%$ cellularity in tumour and normal cell populations, respectively. MSI analysis was carried out using five or more microsatellite markers from the NCI recommended panel of 10 microsatellite markers; these markers consist of mononucleotides BAT-25, BAT-26, BAT-40, and BAT-34C4, dinucleotides D2S123, D5S346, ACTC, D18S55, and D10S197, and one penta-mono-tetra compound marker, MYC-L (Boland et al, 1998). The presence of altered/additional bands that resulted from the tumour PCRamplified product, when compared with the matched normal colon PCR product, indicated MSI. Tumours were classified as MSI high (MSI-H, $\geqslant 30 \%$ unstable markers among all markers tested), MSI low (MSI-L, $<30 \%$ markers unstable) or microsatellite stable (MSS, no unstable markers) as per NCI recommended guidelines for MSI testing (Boland et al, 1998). MSI-L and MSS groups were combined into one group, hereafter referred to as simply 'MSS/L', for analysis purposes. Primer sequences and PCR amplification conditions for MSI testing have been described earlier (Raptis et al, 2007).

\section{Statistical analysis}

The associations of ApoE2 and ApoE4 with colorectal cancer incidence, and with colorectal cancer subsets (MSI-H and MSS/L) were evaluated with a two-sided Pearson's $\chi^{2}$ test, in which a $P$-value of less than 0.05 was considered statistically significant. Unconditional logistic regression was also used to evaluate the association between ApoE2 and ApoE4 and CRC and its subsets, after adjusting for age and sex. The dietary differences between all CRC cases, or subsets stratified by tumour MSI status, and 
unaffected controls were evaluated using Pearson's $\chi^{2}$ or Fisher's exact test and with unconditional logistic regression, after adjusting for age and sex. Dietary differences between CRC subsets (MSI-H, MSS/L) and unaffected controls were also examined by ApoE4 and ApoE2 carrier status using unconditional logistic regression. In addition, we also examined differences in tumour location, stage and grade between MSI-H and MSS/L CRCs using Pearson's $\chi^{2}$ test and unconditional logistic regression. Chi-square and Fisher's exact tests, and logistic regression were performed with SAS version 9.0 (SAS Institute, Cary, NC, USA). All statistical tests were two-sided with a $P$-value $<0.05$ considered significant.

\section{RESULTS}

\section{Distribution of genotypes and alleles}

We genotyped a total of 757 CRC cases for Cys112Arg (rs429358) and 779 CRC cases for Arg158Cys (rs7412) that give rise to ApoE4 and ApoE2 protein isoforms, respectively. We also genotyped 911 controls for ApoE2 and 864 controls for ApoE4 polymorphisms. Both polymorphisms are in Hardy-Weinberg equilibrium among the control population. A typical RFLP HhaI digest is shown in Supplementary Figure 1. The distribution of ApoE2 and ApoE4 genotypes between all cases and controls as well as cases stratified by tumour MSI status is shown in Table 1. The frequency of the ApoE4 allele among the CRC cases and unaffected controls was 13.6 and $14.8 \%$, respectively. The frequency of the ApoE2 allele among the CRC cases and unaffected controls was 7.0 and $7.6 \%$, respectively. We did not observe any statistically significant differences in genotype frequencies between all CRC cases or CRC subsets and unaffected controls (Table 1).

\section{Analysis of ApoE isoforms and dietary factors in CRC}

We observed statistically significant associations of red meat consumption $(P<0.001)$, total fat intake $(P<0.001)$, saturated fat intake $(P=0.002)$, and dietary cholesterol $(P=0.003)$ with CRC; however, dietary folacin $(P=0.14)$ or alcohol intake $(P=0.38)$ did not show such association (Table 2). We did not observe any differences in dietary associations between CRC subsets stratified by tumour MSI status, except for the inverse association between drinking more than two alcoholic beverages per week and MSI-H CRCs (Table 3).

Among ApoE4 variant allele carriers we observed a statistically significant association between high red meat consumption (more than four servings per week) and the risk of MSI-H CRCs when compared with the controls $(\mathrm{OR}=4.62,95 \% \mathrm{CI} 1.20-17.77)$ (Table 4A). This association was not observed among non-ApoE4 carriers (Table 4B). However, among non-ApoE4 carriers a statistically significant association between red meat consumption (two or more servings of red meat per week) and the risk of MSS/L CRCs was observed when compared with the controls (for 2-4 red meat servings per week $\mathrm{OR}=1.51,95 \%$ CI $1.10-2.07$, and for more than four red meat servings per week $\mathrm{OR}=1.80,95 \% \mathrm{CI}$ $1.30-2.48$ ) (Table 4B).

In contrast to ApoE4, we did not observe any statistically significant associations in ApoE2 carriers between dietary factors and CRC subsets (Table 5A). Similar to non-ApoE4 carriers, we observed statistically significant associations among non-ApoE2 carriers of red meat intake, total fat, saturated fat, and cholesterol intake with the risk of MSS/L and MSI-H CRCs when compared with the controls (Table $5 \mathrm{~B}$ ).

Among the CRC cases, we observed that MSI-H tumours occurred more proximally $(P<0.001)$, and were statistically significantly associated with a higher tumour grade $(P<0.001)$ when compared with the MSS/L tumours (Supplementary Table). We did not observe any differences in tumour stage between MSI-H and MSS/L CRCs.

\section{DISCUSSION}

This is the first study, to our knowledge, to examine the relationship between ApoE isoforms and MSI status in CRC. We observed that diets rich in fat or red meat increase the risk of CRC irrespective of tumour MSI status. We did not detect any differences in dietary folacin or alcohol intake between CRC cases and controls (Table 2), although it would appear that more than two alcoholic drinks per week might have a protective effect against MSI-H CRCs (Table 3). There were no associations between ApoE genotypes and CRC. When stratified by ApoE4 carrier status, red meat diet appears to increase the risk of MSI-H CRCs among ApoE4 carriers and MSS/MSI-L CRCs among non-ApoE4 carriers

Table I Distribution of ApoE genotypes by cases and controls

\begin{tabular}{lcccc}
\hline Variable & All cases $\mathbf{N}(\%)$ & Controls $\mathbf{N}(\%)$ & P-value & OR (95\% Cl) all cases vs controls \\
\hline ApoE4 & & & & 1.00 (Referent) \\
TT & $568(75.0)$ & $634(73.4)$ & 0.56 & $0.94(0.75,1.19)$ \\
CT & $172(22.7)$ & $204(23.6)$ & & $0.73(0.39,1.36)$ \\
CC & $17(2.2)$ & $26(3.0)$ & & 1.00 (Referent) \\
ApoE2 & & & $0.95(0.72,1.25)$ \\
TT & $673(86.4)$ & $779(85.5)$ & 0.69 & $0.58(0.14,2.32)$ \\
CT & $103(13.2)$ & $126(13.8)$ & &
\end{tabular}

MSS/L N (\%) MSI-H N (\%)

OR $(95 \% \mathrm{Cl}) \mathrm{MSS} / \mathrm{L}$ vs controls OR $(95 \% \mathrm{Cl}) \mathrm{MSI}-\mathrm{H}$ vs controls

\begin{tabular}{|c|c|c|c|c|c|c|}
\hline \multicolumn{7}{|l|}{ ApoE4 } \\
\hline TT & 391 (75.0) & $63(73.3)$ & $634(73.4)$ & 0.85 & 1.00 (Referent) & I.00 (Referent) \\
\hline $\mathrm{CC}$ & ||$(2.1)$ & $3(3.5)$ & $26(3.0)$ & & $0.69(0.34,1.40)$ & $1.16(0.34,3.94)$ \\
\hline TT & $54 \mid(86.8)$ & 94 (84.7) & 779 (85.5) & 0.70 & 1.00 (Referent) & I.00 (Referent) \\
\hline CT/CC & $82(13.2)$ & $17(15.3)$ & $132(14.5)$ & & $0.89(0.66,1.20)$ & $1.07(0.62,1.85)$ \\
\hline
\end{tabular}

ApoE2 represents ApoE protein with I I2Cys/ I58Cys residues, ApoE4 represents ApoE protein with I I Arg/I 58Arg residues, MSI-H = high frequency microsatellite instability, $\mathrm{MSS} / \mathrm{L}=$ microsatellite stable/low-frequency microsatellite instability, homozygous wild-type allele carriers were considered as the referent groups. 
Table 2 Association of sex, age at diagnosis, red meat intake (servings per week), total fat intake (grams), saturated fat intake (grams), cholesterol intake (milligrams), dietary folacin (milligrams) and alcohol intake (drinks/week) between CRC cases and controls

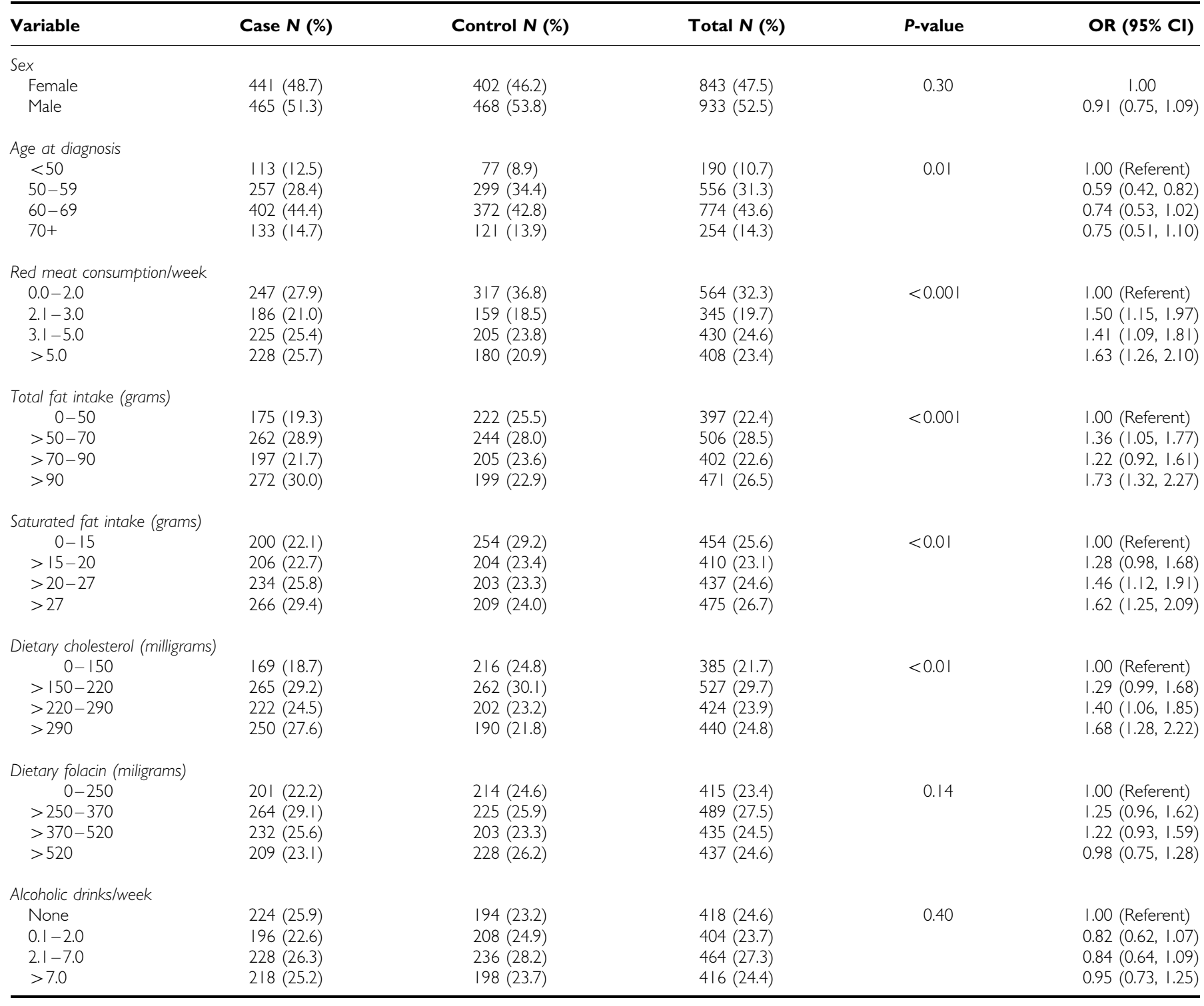

$\mathrm{Cl}=$ confidence interval; $\mathrm{OR}=$ odds ratios adjusted for age and sex. All samples with unavailable data have been omitted from the analyses. Female participants, participants with age $<50$ along with lowest dietary groups have been used as the referent goups.

(Table 4). There is a borderline significant interaction between the ApoE4 allele, and red meat intake with respect to MSI-H CRCs $(P=0.06)$, whereas no significant interaction is detected between ApoE4 and red meat with respect to MSS CRCs $(P=0.13)$. Previous studies on red meat consumption and microsatellite instability have shown inconsistent results (Palli et al, 2001; Wu et al, 2001; Diergaarde et al, 2003). Although ApoE4 isoform and fat-rich diets are a high-risk combination for chronic heart disease and Alzheimer's disease, they seem to play a moderate role in the development of either CRC subtype (Table 4B). Associations with dietary factors in non-ApoE2 carriers are consistent with our overall findings (Table 5B). There were no significant associations among ApoE2 carriers, but the power was low (Table 5A).

The link between red meat intake and CRC has been known for many years (McKeown-Eyssen and Bright-See, 1984; Norat et al, 2005; Larsson and Wolk, 2006). Red meat contains high levels of haemoglobin, myoglobin, and cytochromes which are converted into denatured protein-hemes, hemichromes, and hemochromes, on cooking (Tappel, 2007). Free and coordinated hemes preferentially catalyse oxidative reactions that can damage DNA, proteins, lipids, and other nucleic acids (Tappel, 2007). In addition, heme also damages colonic mucosa and stimulates epithelial proliferation in animal models (Sesink et al, 1999). Red meat diet also leads to the formation of hetrocyclic amines and the endogenous formation of N-nitroso compounds (NOCs) (Cross and Sinha, 2004), which are known potent and organ-specific carcinogens (Magee and Barnes, 1956; Preussmann, 1984). Rats that were fed red meat diets showed significantly greater amounts of DNA single-strand breaks, double-strand breaks, and colonic mucous layer thinning than rats that were fed white meat diet (Toden et al, 2007).

ApoE has been well established to mediate the cellular uptake of lipoproteins by binding to the low-density lipoprotein receptor and the low-density lipoprotein receptor-related protein (LRP) 
Table 3 Association of sex, age at diagnosis, and dietary factors between CRC cases stratified by MSI tumour status and controls

\begin{tabular}{|c|c|c|c|c|c|c|c|}
\hline Variable & $\begin{array}{c}\text { Controls } \\
N(\%)\end{array}$ & $\begin{array}{l}\text { MSS/L } \\
\text { N (\%) }\end{array}$ & $\begin{array}{l}\text { MSI-H } \\
\text { N (\%) }\end{array}$ & $\begin{array}{l}\text { Total } \\
N(\%)\end{array}$ & $P$-value & $\begin{array}{c}\text { OR }(95 \% \mathrm{Cl}) \\
\text { MSS/L vs controls }\end{array}$ & $\begin{array}{l}\text { OR }(95 \% \mathrm{Cl}) \\
\text { MSI-H vs controls }\end{array}$ \\
\hline \multicolumn{8}{|l|}{ Sex } \\
\hline \multicolumn{8}{|l|}{ Age at diagnosis } \\
\hline$<50$ & $77(8.9)$ & $75(11.7)$ & $15(13.4)$ & $167(10.3)$ & \multirow[t]{2}{*}{0.01} & I.00 (Referent) & 1.00 (Referent) \\
\hline $70+$ & $121(13.9)$ & $96(15.0)$ & $27(24.1)$ & $244(15.1)$ & & $0.81(0.54,1.23)$ & $1.15(0.57,2.29)$ \\
\hline \multicolumn{8}{|c|}{ Red meat consumption/week } \\
\hline $0.0-2.0$ & $317(36.8)$ & $170(27.2)$ & $30(27.3)$ & $517(32.4)$ & \multirow{4}{*}{$<0.01$} & I.00 (Referent) & 1.00 (Referent) \\
\hline $2.1-3.0$ & $159(18.5)$ & $134(2 \mid .5)$ & $25(22.7)$ & $318(19.9)$ & & $1.57(1.17,2.11)$ & $1.66(0.95,2.92)$ \\
\hline $3.1-5.0$ & 205 (23.8) & $162(26.0)$ & $29(26.4)$ & $396(24.8)$ & & $1.47(1.12,1.95)$ & $1.49(0.87,2.56)$ \\
\hline$>5.0$ & $180(20.9)$ & $158(25.3)$ & $26(23.6)$ & $364(22.8)$ & & $1.64(1.23,2.17)$ & $1.53(0.88,2.66)$ \\
\hline \multicolumn{8}{|l|}{ Total fat intake } \\
\hline $0-50$ & $222(25.5)$ & $122(19.1)$ & $20(17.9)$ & 364 (22.4) & \multirow[t]{4}{*}{0.01} & I.00 (Referent) & I.00 (Referent) \\
\hline$>50-70$ & $244(28.0)$ & $189(29.5)$ & $30(26.8)$ & $463(28.5)$ & & $1.41(1.05,1.89)$ & $1.36(0.75,2.47)$ \\
\hline$>70-90$ & $205(23.6)$ & $140(21.9)$ & $27(24.1)$ & $372(22.9)$ & & $1.24(0.91,1.69)$ & $1.46(0.80,2.69)$ \\
\hline$>90$ & $199(22.9)$ & $189(29.5)$ & $35(31.3)$ & $423(26.1)$ & & $1.73(1.28,2.33)$ & $1.95(1.09,3.49)$ \\
\hline \multicolumn{8}{|c|}{ Total fat intake (tertiles) } \\
\hline $0-57$ & $315(36.2)$ & $183(28.6)$ & $31(27.7)$ & $529(32.6)$ & \multirow[t]{3}{*}{$<0.01$} & I.00 (Referent) & I.00 (Referent) \\
\hline$>57-83$ & $300(34.5)$ & $226(35.3)$ & $37(35.3)$ & $563(34.7)$ & & $1.30(1.01,1.67)$ & $1.25(0.76,2.07)$ \\
\hline$>83$ & $255(29.3)$ & $231(36.1)$ & $44(39.3)$ & $530(32.7)$ & & $1.56(1.21,2.01)$ & $1.75(1.08,2.86)$ \\
\hline \multicolumn{8}{|c|}{ Saturated fat intake } \\
\hline $0-15$ & $254(29.2)$ & $140(21.9)$ & $22(19.6)$ & $416(25.6)$ & $<0.01$ & I.00 (Referent) & 1.00 (Referent) \\
\hline Dietary choleste & & & & & & & \\
\hline $0-150$ & $216(24.8)$ & $114(17.8)$ & $24(21.4)$ & $354(21.8)$ & 0.02 & I.00 (Referent) & I.00 (Referent) \\
\hline$>150-220$ & $262(30.1)$ & $187(29.2)$ & $30(26.8)$ & $479(29.5)$ & & 1.35 (1.01, 1.82) & $1.03(0.58,1.82)$ \\
\hline$>220-290$ & $202(23.2)$ & $168(26.3)$ & $25(22.3)$ & $395(24.4)$ & & $1.58(1.16,2.14)$ & $1.11(0.62,2.01)$ \\
\hline$>290$ & $190(21.8)$ & $17 \mid(26.7)$ & $33(29.5)$ & $394(24.3)$ & & I.71 $(1.25,2.32)$ & $1.56(0.89,2.74)$ \\
\hline Dietary choleste & & & & & & & \\
\hline $0-180$ & $334(38.4)$ & $190(29.7)$ & $42(37.5)$ & $566(34.9)$ & $<0.01$ & I.00 (Referent) & I.00 (Referent) \\
\hline$>180-260$ & 267 (30.7) & $219(34.2)$ & $29(25.9)$ & $515(31.8)$ & & $1.44(1.12,1.86)$ & $0.86(0.52,1.42)$ \\
\hline$>260$ & $269(30.9)$ & $231(36.1)$ & $41(36.6)$ & $54 I(33.4)$ & & $1.51(1.18,1.94)$ & $1.21(0.77,1.92)$ \\
\hline Dietary folacin & & & & & & & \\
\hline $0-250$ & $214(24.6)$ & $137(21.4)$ & $24(21.4)$ & $375(23.1)$ & 0.34 & I.00 (Referent) & I.00 (Referent) \\
\hline$>250-370$ & $225(25.9)$ & $192(30.0)$ & $32(28.6)$ & $449(27.7)$ & & $1.33(1.00,1.78)$ & $1.27(0.72,2.22)$ \\
\hline$>370-520$ & $203(23.3)$ & $165(25.8)$ & $27(24.1)$ & $395(24.4)$ & & $1.27(0.94,1.71)$ & $1.19(0.66,2.12)$ \\
\hline$>520$ & $228(26.2)$ & $146(22.8)$ & $29(25.9)$ & $403(24.8)$ & & $1.00(0.74,1.35)$ & $1.13(0.64,2.01)$ \\
\hline Dietary folacin ( & & & & & & & \\
\hline $0-290$ & $299(34.4)$ & $202(31.6)$ & 38 (33.9) & 539 (33.2) & 0.37 & I.00 (Referent) & I.00 (Referent) \\
\hline$>290-460$ & $277(31.8)$ & $235(36.7)$ & $35(31.3)$ & $547(33.7)$ & & $1.26(0.98,1.61)$ & $0.99(0.61,1.62)$ \\
\hline$>460$ & $294(33.8)$ & $203(31.7)$ & $39(34.8)$ & $536(33.0)$ & & $1.02(0.79,1.32)$ & $1.04(0.65,1.68)$ \\
\hline Alcoholic drinks/ & & & & & & & \\
\hline None & $194(23.2)$ & I 46 (23.9) & $39(36.1)$ & $379(24.4)$ & 0.11 & I.00 (Referent) & I.00 (Referent) \\
\hline $0.1-2.0$ & $208(24.9)$ & 140 (22.9) & $25(23.1)$ & $373(24.0)$ & & $0.89(0.66,1.21)$ & $0.60(0.35,1.02)$ \\
\hline $2.1-7.0$ & $236(28.2)$ & I7| (28.0) & $23(21.3)$ & $430(27.7)$ & & $0.96(0.72,1.29)$ & $0.48(0.28,0.84)$ \\
\hline$>7.0$ & 198 (23.7) & $154(25.2)$ & $21(19.4)$ & $373(24.0)$ & & $1.03(0.77,1.40)$ & $0.53(0.30,0.93)$ \\
\hline
\end{tabular}


Table 4 Association of dietary factors between CRC cases stratified by MSI tumour status and controls by ApoE4 allele carrier status

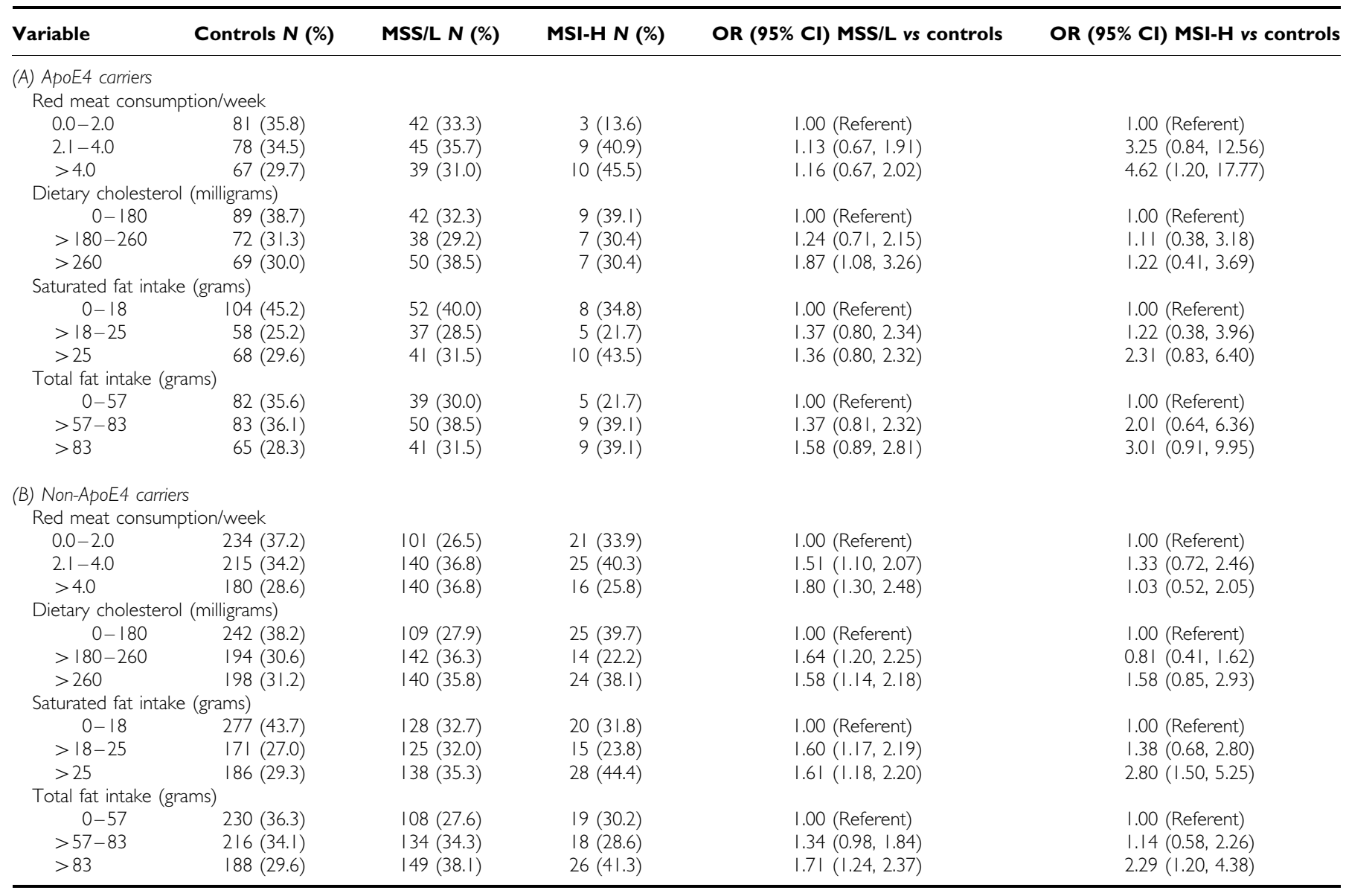

$\mathrm{Cl}=$ confidence interval; $\mathrm{MSI}-\mathrm{H}=$ high frequency microsatellite instability; $\mathrm{MSS} / \mathrm{L}=$ microsatellite stable/low-frequency microsatellite instability; $\mathrm{OR}=$ odds ratios adjusted for age and sex. All samples with unavailable data have been omitted from the analyses. Lowest dietary groups have been used as the referent groups.

(Lund et al, 1989; Yamada et al, 1992). However, ApoE also performs other crucial functions, and aberration of these functions may lead to cancer (Vogel et al, 1994; Grocott et al, 2001; Niemi et al, 2002; Cedazo-Minguez et al, 2003). ApoE binds heparin and proteoglycans with very high affinity and inhibits proliferation of several cell types such as: endothelial cells, lymphocytes, smooth muscle cells, and several types of tumour cells (Cardin et al, 1988; Ji et al, 1993; Browning et al, 1994; Vogel et al, 1994; Ishigami et al, 1998). In vitro studies suggest that treatment of colon cancer cell line HT29 with ApoE enhanced cell polarity by translocating $\beta$-catenin from the cytoplasm to cell-cell adhesion sites (Niemi et al, 2002). ApoE is a potent inhibitor of cell proliferation and de novo DNA synthesis (Vogel et al, 1994). Functional studies on ApoE isoforms showed that ApoE4, but not wild-type ApoE, significantly inhibits GSK-3 $\beta$ and increases the amount of active PKB (which further inactivates GSK-3 $\beta$ ), leading to enhanced $\beta$-catenin translocation into the nucleus (Cedazo-Minguez et al, 2003 ). Nuclear $\beta$-catenin promotes transcription of genes involved in cell survival and division (Behrens et al, 1996; Molenaar et al, 1996; Pap and Cooper, 1998). These results would indicate that ApoE4 has pro-proliferative and anti-apoptotic properties.

Taken together, we propose that the selective effects of red meat diet on MSI-H CRC in ApoE4 carriers may be due to the antiapoptotic and pro-proliferative effects of ApoE4. Heme and NOCs from red meat diets cause oxidative damage and DNA adduct formation, but rather than initiating cell cycle arrest and DNA repair, ApoE4-expressing cells induce pro-survival and proliferative signals. This would place a substantial strain on DNA repair machinery until a certain threshold level is reached beyond which the DNA repair mechanism is ineffective and genomic stability is compromised. Such cells would not undergo apoptosis even when extensive DNA damage is present. In addition, ApoE4 has poor antioxidant properties, compared with ApoE2, and combined with its proinflammatory functions may further exacerbate the tumourigenic process (Miyata and Smith, 1996; Jofre-Monseny et al, 2007). Conversely, ApoE2 and wild-type ApoE carriers would be able to better modulate aberrant cellular proliferation, inhibit oxidating and proinflammatory agents, allowing DNA repair machinery to more effectively repair DNA damage. Studies including fruits, vegetables, and antioxidant nutrients and their interaction with ApoE isoforms will further clarify this possible mechanism.

The main strength of our study is a well-characterised population. The frequencies of ApoE genotypes in our population are very similar to those of reports published earlier (Watson et al, 2003; Slattery et al, 2005; Bennet et al, 2007). We observed a strong association of MSI-H CRCs with female patients (Table 3), proximal colon location and higher tumour grades (Supplementary Table) consistent with reports published earlier (Thibodeau et al, 1993; Gryfe et al, 2000; Samowitz et al, 2001; Ribic et al, 2003). Limitations of our study are the small sample size of MSI-H CRCs and the low frequency of the ApoE2 polymorphism, which reduces our power to observe significant interactions among ApoE genotypes and dietary variables. Although the findings presented in this study need to be independently validated in another population, further characterisation of ApoE polymorphisms and 
Table 5 Association of dietary factors between CRC cases stratified by MSI tumour status and controls by ApoE2 allele carrier status

\begin{tabular}{|c|c|c|c|c|c|}
\hline Variable & Controls N (\%) & MSS/L N (\%) & MSI-H N (\%) & OR $(95 \% \mathrm{Cl}) \mathrm{MSS} / \mathrm{L}$ vs controls & OR $(95 \% \mathrm{Cl}) \mathrm{MSI}-\mathrm{H}$ vs controls \\
\hline \multicolumn{6}{|c|}{ Red meat consumption/week } \\
\hline $0.0-2.0$ & $40(30.3)$ & $17(21.0)$ & $4(25.0)$ & 1.00 (Referent) & 1.00 (Referent) \\
\hline$>4.0$ & $45(34.1)$ & $34(42.0)$ & $4(25.0)$ & $1.76(0.85,3.65)$ & $0.87(0.20,3.80)$ \\
\hline \multicolumn{6}{|c|}{ Dietary cholesterol (milligrams) } \\
\hline $0-180$ & $40(30.3)$ & $25(30.5)$ & $8(47.1)$ & 1.00 (Referent) & 1.00 (Referent) \\
\hline \multicolumn{6}{|c|}{ Saturated fat intake (grams) } \\
\hline $0-18$ & $50(37.9)$ & $26(31.7)$ & $7(4 \mid .2)$ & 1.00 (Referent) & 1.00 (Referent) \\
\hline$>18-25$ & $32(24.2)$ & $29(35.4)$ & $5(29.4)$ & $1.84(0.90,3.73)$ & $1.38(0.39,4.89)$ \\
\hline$>25$ & $50(37.9)$ & $27(32.9)$ & $5(29.4)$ & $1.12(0.57,2.21)$ & $0.86(0.25,2.98)$ \\
\hline \multicolumn{6}{|c|}{ Total fat intake (grams) } \\
\hline $0-57$ & $40(30.3)$ & $26(31.7)$ & $8(47.1)$ & I.00 (Referent) & 1.00 (Referent) \\
\hline$>57-83$ & $44(33.3)$ & $25(30.5)$ & $2(11.7)$ & $0.85(0.42,1.73)$ & $0.24(0.05,1.20)$ \\
\hline $2.1-4.0$ & $263(34.2)$ & $192(36.4)$ & $40(43.0)$ & $1.41(1.07,1.85)$ & $1.76(1.04,2.98)$ \\
\hline$>4.0$ & $217(28.3)$ & $186(35.3)$ & $27(29.0)$ & $1.68(1.27,2.23)$ & $1.51(0.85,2.69)$ \\
\hline \multicolumn{6}{|c|}{ Dietary cholesterol (milligrams) } \\
\hline $0-180$ & 309 (39.7) & $162(29.9)$ & $33(35.1)$ & 1.00 (Referent) & 1.00 (Referent) \\
\hline$>180-260$ & $239(30.7)$ & $185(34.2)$ & $26(27.7)$ & $1.52(1.16,2.00)$ & $1.19(0.68,2.06)$ \\
\hline$>260$ & $231(29.6)$ & $194(35.9)$ & $35(37.2)$ & $1.67(1.26,2.21)$ & $1.89(1.11,3.23)$ \\
\hline \multicolumn{6}{|c|}{ Saturated fat intake (grams) } \\
\hline $0-18$ & $357(45.8)$ & $189(34.9)$ & $28(29.8)$ & 1.00 (Referent) & 1.00 (Referent) \\
\hline$>18-25$ & $207(26.6)$ & $164(30.3)$ & $24(25.5)$ & $1.54(1.17,2.02)$ & $1.67(0.94,2.98)$ \\
\hline$>25$ & $215(27.6)$ & $188(34.8)$ & $42(44.7)$ & $1.72(1.31,2.26)$ & $3.26(1.92,5.54)$ \\
\hline \multicolumn{6}{|c|}{ Total fat intake (grams) } \\
\hline $0-18$ & $289(37.1)$ & $|5|(28.0)$ & $23(24.5)$ & 1.00 (Referent) & 1.00 (Referent) \\
\hline$>18-25$ & $273(35.0)$ & $195(36.0)$ & $34(36.2)$ & $1.39(1.06,1.83)$ & $1.76(1.00,3.09)$ \\
\hline$>25$ & $217(27.9)$ & $195(36.0)$ & $37(39.3)$ & $1.83(1.37,2.43)$ & $2.92(1.65,5.18)$ \\
\hline
\end{tabular}

$\mathrm{Cl}=$ confidence interval; $\mathrm{MSI}-\mathrm{H}=$ high frequency microsatellite instability; MSS/L = microsatellite stable/ low frequency microsatellite instability; OR = odds ratios adjusted for age and sex. All samples with unavailable data have been omitted from the analyses. Lowest dietary groups have been used as the referent groups

dietary or environmental factors, may provide new insights into the gene-diet and gene-environment interactions and their contribution to incidence and progression of colon cancer or its subtypes.

\section{ACKNOWLEDGEMENTS}

This work was supported by the American Institute for Cancer Research Grant 99B055 and Canadian Institutes of Health Research Grant MOP43950 (BB and JK); by the National Cancer Institute, National Institutes of Health under Request For Applications CA-95-011 and through cooperative agreements with members of the colon family registry and Principal Investigators (U01 CA074783 awarded to Ontario Registry for Studies of Familial Colorectal Cancer). The content of this article does not necessarily reflect the views or policies of the National Cancer Institute or any of the collaborating centers in Cancer Family Registry (CFRs), nor does mention of trade names, commercial products, or organisations imply endorsement by the US Government or CFR. MM is a Research Student of the Canadian Cancer Society through an award from the National Cancer Institute of Canada (018668). MM was also supported by the Samuel Lunenfeld Research Institute and the Team in Interdisciplinary Research in Colorectal Cancer (with funding from the Canadian Institutes of Health Research). The authors had full responsibility for the design of the study, the collection of data, the analysis and interpretation of the data, the decision to submit the article for publication, and the writing of the article.

\section{Conflict of interest}

The authors declare no conflict of interest.

Supplementary Information accompanies the paper on British Journal of Cancer website (http://www.nature.com/bjc)

\section{REFERENCES}

Alexander J, Watanabe T, Wu TT, Rashid A, Li S, Hamilton SR (2001) Histopathological identification of colon cancer with microsatellite instability. Am J Pathol 158: 527-535

Bautista D, Obrador A, Moreno V, Cabeza E, Canet R, Benito E, Bosch X, Costa J (1997) Ki-ras mutation modifies the protective effect of dietary monounsaturated fat and calcium on sporadic colorectal cancer. Cancer Epidemiol Biomarkers Prev 6: 57-61

Behrens J, von Kries JP, Kuhl M, Bruhn L, Wedlich D, Grosschedl R, Birchmeier W (1996) Functional interaction of beta-catenin with the transcription factor LEF-1. Nature 382: 638-642 
Bennet AM, Di Angelantonio E, Ye Z, Wensley F, Dahlin A, Ahlbom A, Keavney B, Collins R, Wiman B, de Faire U, Danesh J (2007) Association of apolipoprotein $\mathrm{E}$ genotypes with lipid levels and coronary risk. JAMA 298: 1300 - 1311

Boland CR, Thibodeau SN, Hamilton SR, Sidransky D, Eshleman JR, Burt RW, Meltzer SJ, Rodriguez-Bigas MA, Fodde R, Ranzani GN, Srivastava S (1998) A National Cancer Institute Workshop on Microsatellite Instability for cancer detection and familial predisposition: development of international criteria for the determination of microsatellite instability in colorectal cancer. Cancer Res 58: 5248-5257

Bretsky P, Guralnik JM, Launer L, Albert M, Seeman TE (2003) The role of APOE-epsilon4 in longitudinal cognitive decline: MacArthur studies of successful aging. Neurology 60: $1077-1081$

Browning PJ, Roberts DD, Zabrenetzky V, Bryant J, Kaplan M, Washington RH, Panet A, Gallo RC, Vogel T (1994) Apolipoprotein E (ApoE), a novel heparin-binding protein inhibits the development of Kaposi's sarcoma-like lesions in BALB/c nu/nu mice. J Exp Med 180: $1949-1954$

Butler WJ, Ryan P, Roberts-Thomson IC (2001) Metabolic genotypes and risk for colorectal cancer. J Gastroenterol Hepatol 16: 631-635

Cardin AD, Bowlin TL, Krstenansky JL (1988) Inhibition of lymphocyte proliferation by synthetic peptides homologous to human plasma apolipoproteins B and E. Biochem Biophys Res Commun 154: 741-745

Cedazo-Minguez A, Popescu BO, Blanco-Millan JM, Akterin S, Pei JJ, Winblad B, Cowburn RF (2003) Apolipoprotein E and beta-amyloid (1-42) regulation of glycogen synthase kinase-3beta. J Neurochem 87: $1152-1164$

Corder EH, Saunders AM, Strittmatter WJ, Schmechel DE, Gaskell PC, Small GW, Roses AD, Haines JL, Pericak-Vance MA (1993) Gene dose of apolipoprotein E type 4 allele and the risk of Alzheimer's disease in late onset families. Science 261: $921-923$

Cotterchio M, Boucher BA, Kreiger N, Mills CA, Thompson LU (2008) Dietary phytoestrogen intake-lignans and isoflavones-and breast cancer risk (Canada). Cancer Causes Control 19(3): 259-272

Cotterchio M, McKeown-Eyssen G, Sutherland H, Buchan G, Aronson M, Easson AM, Macey J, Holowaty E, Gallinger S (2000) Ontario familial colon cancer registry: methods and first-year response rates. Chronic Dis Can 21: $81-86$

Cross AJ, Sinha R (2004) Meat-related mutagens/carcinogens in the etiology of colorectal cancer. Environ Mol Mutagen 44: 44-55

Debruyne PR, Bruyneel EA, Karaguni IM, Li X, Flatau G, Muller O, Zimber A, Gespach C, Mareel MM (2002) Bile acids stimulate invasion and haptotaxis in human colorectal cancer cells through activation of multiple oncogenic signaling pathways. Oncogene 21: 6740-6750

Diergaarde B, Braam H, van Muijen GN, Ligtenberg MJ, Kok FJ, Kampman E (2003) Dietary factors and microsatellite instability in sporadic colon carcinomas. Cancer Epidemiol Biomarkers Prev 12: 1130-1136

Elsaleh H, Shannon B, Iacopetta B (2001) Microsatellite instability as a molecular marker for very good survival in colorectal cancer patients receiving adjuvant chemotherapy. Gastroenterology 120: 1309-1310

Emmons KM, McBride CM, Puleo E, Pollak KI, Marcus BH, Napolitano M, Clipp E, Onken J, Farraye FA, Fletcher R (2005) Prevalence and predictors of multiple behavioral risk factors for colon cancer. Prev Med 40: $527-534$

Ferrari P, Jenab M, Norat T, Moskal A, Slimani N, Olsen A, Tjonneland A, Overvad K, Jensen MK, Boutron-Ruault MC, Clavel-Chapelon F, Morois S, Rohrmann S, Linseisen J, Boeing H, Bergmann M, Kontopoulou D, Trichopoulou A, Kassapa C, Masala G, Krogh V, Vineis P, Panico S, Tumino R, van Gils CH, Peeters P, Bueno-de-Mesquita HB, Ocke MC, Skeie G, Lund E, Agudo A, Ardanaz E, Lopez DC, Sanchez MJ, Quiros JR, Amiano P, Berglund G, Manjer J, Palmqvist R, Van Guelpen B, Allen N, Key T, Bingham S, Mazuir M, Boffetta P, Kaaks R, Riboli E (2007) Lifetime and baseline alcohol intake and risk of colon and rectal cancers in the European prospective investigation into cancer and nutrition (EPIC). Int J Cancer 121: 2065-2072

Gioia L, Vogt LJ, Freeman WM, Flood A, Vogt BA, Vrana KE (1998) PCR-based apolipoprotein E genotype analysis from archival fixed brain. J Neurosci Methods 80: 209-214

Grocott HP, Newman MF, El-Moalem H, Bainbridge D, Butler A, Laskowitz DT (2001) Apolipoprotein E genotype differentially influences the proinflammatory and anti-inflammatory response to cardiopulmonary bypass. J Thorac Cardiovasc Surg 122: $622-623$

Gryfe R, Kim H, Hsieh ET, Aronson MD, Holowaty EJ, Bull SB, Redston M, Gallinger S (2000) Tumor microsatellite instability and clinical outcome in young patients with colorectal cancer. $N$ Engl J Med 342: 69-77
Ishigami M, Swertfeger DK, Granholm NA, Hui DY (1998) Apolipoprotein E inhibits platelet-derived growth factor-induced vascular smooth muscle cell migration and proliferation by suppressing signal transduction and preventing cell entry to G1 phase. J Biol Chem 273: 20156-20161

Jemal A, Siegel R, Ward E, Murray T, Xu J, Thun MJ (2007) Cancer statistics, 2007. CA Cancer J Clin 57: 43-66

Ji ZS, Brecht WJ, Miranda RD, Hussain MM, Innerarity TL, Mahley RW (1993) Role of heparan sulfate proteoglycans in the binding and uptake of apolipoprotein E-enriched remnant lipoproteins by cultured cells. J Biol Chem 268: 10160 - 10167

Jofre-Monseny L, de Pascual-Teresa S, Plonka E, Huebbe P, BoeschSaadatmandi C, Minihane AM, Rimbach G (2007) Differential effects of apolipoprotein $\mathrm{E} 3$ and $\mathrm{E} 4$ on markers of oxidative status in macrophages. Br J Nutr 97: 864-871

Kervinen K, Sodervik H, Makela J, Lehtola J, Niemi M, Kairaluoma MI, Kesaniemi YA (1996) Is the development of adenoma and carcinoma in proximal colon related to apolipoprotein E phenotype? Gastroenterology 110: $1785-1790$

Larsson SC, Wolk A (2006) Meat consumption and risk of colorectal cancer: a meta-analysis of prospective studies. Int $J$ Cancer 119: $2657-2664$

Lund H, Takahashi K, Hamilton RL, Havel RJ (1989) Lipoprotein binding and endosomal itinerary of the low density lipoprotein receptor-related protein in rat liver. Proc Natl Acad Sci USA 86: 9318-9322

Lynch HT, de la Chapelle A (2003) Hereditary colorectal cancer. $N$ Engl J Med 348: 919-932

MacLeod MJ, De Lange RP, Breen G, Meiklejohn D, Lemmon H, Clair DS (2001) Lack of association between apolipoprotein E genoype and ischaemic stroke in a Scottish population. Eur J Clin Invest 31: $570-573$

Magee PN, Barnes JM (1956) The production of malignant primary hepatic tumours in the rat by feeding dimethylnitrosamine. $\mathrm{Br} J$ Cancer 10: $114-122$

McKeown-Eyssen GE, Bright-See E (1984) Dietary factors in colon cancer: international relationships. Nutr Cancer 6: 160-170

Minihane AM, Jofre-Monseny L, Olano-Martin E, Rimbach G (2007) ApoE genotype, cardiovascular risk and responsiveness to dietary fat manipulation. Proc Nutr Soc 66: 183-197

Miyata M, Smith JD (1996) Apolipoprotein E allele-specific antioxidant activity and effects on cytotoxicity by oxidative insults and beta-amyloid peptides. Nat Genet 14: 55-61

Molenaar $M$, van de Wetering $M$, Oosterwegel $M$, Peterson-Maduro J, Godsave S, Korinek V, Roose J, Destree O, Clevers H (1996) XTcf-3 transcription factor mediates beta-catenin-induced axis formation in Xenopus embryos. Cell 86: $391-399$

Mrkonjic M, Raptis S, Green RC, Monga N, Daftary D, Dicks E, Younghusband HB, Parfrey PS, Gallinger SS, McLaughlin JR, Knight JA, Bapat B (2007) MSH2 118T >C and MSH6 159C > T promoter polymorphisms and the risk of colorectal cancer. Carcinogenesis 28: $2575-2580$

Niemi M, Hakkinen T, Karttunen TJ, Eskelinen S, Kervinen K, Savolainen MJ, Lehtola J, Makela J, Yla-Herttuala S, Kesaniemi YA (2002) Apolipoprotein E and colon cancer. Expression in normal and malignant human intestine and effect on cultured human colonic adenocarcinoma cells. Eur J Intern Med 13: 37-43

Norat T, Bingham S, Ferrari P, Slimani N, Jenab M, Mazuir M, Overvad K, Olsen A, Tjonneland A, Clavel F, Boutron-Ruault MC, Kesse E, Boeing H, Bergmann MM, Nieters A, Linseisen J, Trichopoulou A, Trichopoulos D, Tountas Y, Berrino F, Palli D, Panico S, Tumino R, Vineis P, Buenode-Mesquita HB, Peeters PH, Engeset D, Lund E, Skeie G, Ardanaz E, Gonzalez C, Navarro C, Quiros JR, Sanchez MJ, Berglund G, Mattisson I, Hallmans G, Palmqvist R, Day NE, Khaw KT, Key TJ, San Joaquin M, Hemon B, Saracci R, Kaaks R, Riboli E (2005) Meat, fish, and colorectal cancer risk: the European prospective investigation into cancer and nutrition. J Natl Cancer Inst 97: 906-916

Palli D, Russo A, Ottini L, Masala G, Saieva C, Amorosi A, Cama A, $\mathrm{D}^{\prime}$ Amico C, Falchetti M, Palmirotta R, Decarli A, Mariani Costantini R, Fraumeni Jr JF (2001) Red meat, family history, and increased risk of gastric cancer with microsatellite instability. Cancer Res 61: 5415-5419

Pap M, Cooper GM (1998) Role of glycogen synthase kinase-3 in the phosphatidylinositol 3-Kinase/Akt cell survival pathway. J Biol Chem 273: $19929-19932$

Preussmann R (1984) Carcinogenic N-nitroso compounds and their environmental significance. Naturwissenschaften 71: 25-30

Rall Jr SC, Weisgraber KH, Mahley RW (1982) Human apolipoprotein E. The complete amino acid sequence. J Biol Chem 257: 4171-4178 
Raptis S, Mrkonjic M, Green RC, Pethe VV, Monga N, Chan YM, Daftary D, Dicks E, Younghusband BH, Parfrey PS, Gallinger SS, McLaughlin JR, Knight JA, Bapat B (2007) MLH1 -93G > A promoter polymorphism and the risk of microsatellite-unstable colorectal cancer. J Natl Cancer Inst 99: $463-474$

Ribic CM, Sargent DJ, Moore MJ, Thibodeau SN, French AJ, Goldberg RM, Hamilton SR, Laurent-Puig P, Gryfe R, Shepherd LE, Tu D, Redston M, Gallinger S (2003) Tumor microsatellite-instability status as a predictor of benefit from fluorouracil-based adjuvant chemotherapy for colon cancer. $N$ Engl J Med 349: $247-257$

Samowitz WS, Curtin K, Ma KN, Schaffer D, Coleman LW, Leppert M, Slattery ML (2001) Microsatellite instability in sporadic colon cancer is associated with an improved prognosis at the population level. Cancer Epidemiol Biomarkers Prev 10: 917-923

Sesink AL, Termont DS, Kleibeuker JH, Van der Meer R (1999) Red meat and colon cancer: the cytotoxic and hyperproliferative effects of dietary heme. Cancer Res 59: 5704-5709

Slattery ML, Curtin K, Anderson K, Ma KN, Edwards S, Leppert M, Potter J, Schaffer D, Samowitz WS (2000) Associations between dietary intake and Ki-ras mutations in colon tumors: a population-based study. Cancer Res 60: $6935-6941$

Slattery ML, Sweeney C, Murtaugh M, Ma KN, Potter JD, Levin TR, Samowitz W, Wolff R (2005) Associations between apoE genotype and colon and rectal cancer. Carcinogenesis 26: $1422-1429$

Tappel A (2007) Heme of consumed red meat can act as a catalyst of oxidative damage and could initiate colon, breast and prostate cancers, heart disease and other diseases. Med Hypotheses 68: 562-564

Thibodeau SN, Bren G, Schaid D (1993) Microsatellite instability in cancer of the proximal colon. Science 260: 816-819

Toden S, Bird AR, Topping DL, Conlon MA (2007) High red meat diets induce greater numbers of colonic DNA double-strand breaks than white meat in rats: attenuation by high-amylose maize starch. Carcinogenesis 28: $2355-2362$
Vogel T, Guo NH, Guy R, Drezlich N, Krutzsch HC, Blake DA, Panet A, Roberts DD (1994) Apolipoprotein E: a potent inhibitor of endothelial and tumor cell proliferation. J Cell Biochem 54: 299-308

Wark PA, Van der Kuil W, Ploemacher J, Van Muijen GN, Mulder CJ, Weijenberg MP, Kok FJ, Kampman E (2006) Diet, lifestyle and risk of K-ras mutation-positive and -negative colorectal adenomas. Int J Cancer 119: $398-405$

Watson MA, Gay L, Stebbings WS, Speakman CT, Bingham SA, Loktionov A (2003) Apolipoprotein E gene polymorphism and colorectal cancer: gender-specific modulation of risk and prognosis. Clin Sci (London) 104: $537-545$

Weisgraber KH, Rall Jr SC, Mahley RW (1981) Human E apoprotein heterogeneity. Cysteine-arginine interchanges in the amino acid sequence of the apo-E isoforms. J Biol Chem 256: 9077-9083

Wilson PW, Schaefer EJ, Larson MG, Ordovas JM (1996) Apolipoprotein E alleles and risk of coronary disease. A meta-analysis. Arterioscler Thromb Vasc Biol 16: 1250 - 1255

Wu AH, Shibata D, Yu MC, Lai MY, Ross RK (2001) Dietary heterocyclic amines and microsatellite instability in colon adenocarcinomas. Carcinogenesis 22: $1681-1684$

Yamada N, Inoue I, Kawamura M, Harada K, Watanabe Y, Shimano H, Gotoda T, Shimada M, Kohzaki K, Tsukada T, Shiomi M, Watanabe Y, Yazaki Y (1992) Apolipoprotein E prevents the progression of atherosclerosis in Watanabe heritable hyperlipidemic rabbits. J Clin Invest 89: 706-711

Zanke BW, Greenwood CM, Rangrej J, Kustra R, Tenesa A, Farrington SM, Prendergast J, Olschwang S, Chiang T, Crowdy E, Ferretti V, Laflamme P, Sundararajan S, Roumy S, Olivier JF, Robidoux F, Sladek R, Montpetit A, Campbell P, Bezieau S, O'Shea AM, Zogopoulos G, Cotterchio M, Newcomb P, McLaughlin J, Younghusband B, Green R, Green J, Porteous ME, Campbell H, Blanche H, Sahbatou M, Tubacher E, Bonaiti-Pellie C, Buecher B, Riboli E, Kury S, Chanock SJ, Potter J, Thomas G, Gallinger S, Hudson TJ, Dunlop MG (2007) Genome-wide association scan identifies a colorectal cancer susceptibility locus on chromosome 8q24. Nat Genet 39: 989-994 